\title{
Psoas compartment block efficacy and safety for perioperative analgesia in the elderly with proximal femur fractures: a randomized controlled study
}

\author{
Kateryna Bielka ${ }^{1 *}$, lurii Kuchyn ${ }^{1}$, Igor Tokar ${ }^{2}$, Valerii Artemenko ${ }^{2}$ and Uliana Kashchii ${ }^{1}$
}

\begin{abstract}
Background: Proximal femur fractures are most common fractures in the elderly and associated with significant mortality and morbidity, with high economic and social impact. Perioperative pain management influence outcomes and mortality after surgery with early mobilization being possible. The goal of the study was to compare the efficacy and safety of the psoas compartment block (PCB) with spinal and general anesthesia.

Methods: We included 90 patients in this randomized controlled study and divided them into three groups. For patients in group 1 ultrasound-guided PCB with bupivacaine $0.125 \% 6-8 \mathrm{ml} / \mathrm{h}$ was performed. Intraoperative anesthesia was provided with $\mathrm{PCB}$ and a sciatic nerve block. Postoperative analgesia include prolonged CPB with bupivacaine $0.125 \%$ 6-8 $\mathrm{ml} / \mathrm{h}$. In group 2 intraoperative spinal anaesthesia were performed. Group 3 patients underwent general sevoflurane inhalation anaesthesia with fentanyl infusion for analgesia. All patients received paracetamol $3 \mathrm{~g} /$ day and dexketoprofen $75 \mathrm{mg} /$ day during hospitalization. On-demand, nalbuphine $5 \mathrm{mg} \mathrm{SC}$ was used for analgesia. Efficacy outcomes were the ICU length of stay and the total duration of hospitalization, number of patients who had severe pain after surgery, incidence of on-demand analgesia, sleep quality, postoperative mobilization time. Safety outcomes include complication incidence.

Results: There were no differences in the duration of ICU stay - gr.1 72 [70-75], gr.2 74 [72-76], gr.3 72 [70-75] hours respectively ( $p=0.29$ ), and the total duration of hospitalization - gr.1144 [170-184], gr.2170 [148-188], gr.3178 [144-200] hours respectively. Patients in gr. 1 had significantly lower nalbuphine consumption in the first $24 \mathrm{~h}$ after surgery and total during hospitalization (0 [0-5] mg versus 15 [10-20] and 20 [15-25] mg in the first $24 \mathrm{~h}$ in groups 2 and 3 , respectively $(p<0.001)$. Gr. 1 had lower number of patients with severe pain (10\% vs. 47 and $60 \%$ in groups 2 and 3 , respectively, $p<0.05)$, lower number of on demand analgesia (0 [0-1] vs. $3[2-4]$ and $4[3,4]$ in groups 2 and 3 , respectively), better sleep quality (8 [7-9] vs. $6[5-7]$ and $4[3,4]$ in groups 2 and 3 , respectively, $p<0.001$ ), significantly faster mobilization after surgery - sitting in bed and getting to his feet. MINS was diagnosed significantly more often in gr. 2 and 3 compared with gr. 1 (OR $995 \mathrm{Cl}$ 1,01-77, $p=0,048$ for gr. 2 and OR $1195 \mathrm{Cl}$ 1,2-91, $p=0$, 03 for gr. 3). However, none of the patients had symptoms of myocardial ischemia and was not diagnosed with myocardial infarction. There were no difference in the incidence of nosocomial pneumonia and delirium.
\end{abstract}

\footnotetext{
*Correspondence: Ekateryna.belka@gmail.com

${ }^{1}$ Postgraduate Department of Surgery, Anesthesiology and Intensive

Care, Bogomolets National Medical University, 13 T. Shevchenko Boulevard, Kiev 01601, Ukraine

Full list of author information is available at the end of the article
}

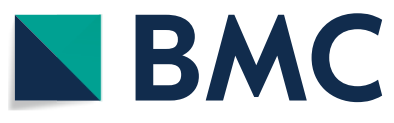

(c) The Author(s) 2021. Open Access This article is licensed under a Creative Commons Attribution 4.0 International License, which permits use, sharing, adaptation, distribution and reproduction in any medium or format, as long as you give appropriate credit to the original author(s) and the source, provide a link to the Creative Commons licence, and indicate if changes were made. The images or other third party material in this article are included in the article's Creative Commons licence, unless indicated otherwise in a credit line to the material. If material is not included in the article's Creative Commons licence and your intended use is not permitted by statutory regulation or exceeds the permitted use, you will need to obtain permission directly from the copyright holder. To view a copy of this licence, visit http://creativecommons.org/licenses/by/4.0/. The Creative Commons Public Domain Dedication waiver (http://creativeco mmons.org/publicdomain/zero/1.0/) applies to the data made available in this article, unless otherwise stated in a credit line to the data. 
Conclusion: Perioperative PCB in elderly patients with a proximal femur fracture could be an effective analgesia technique, as it decrease the number of patients with severe pain, need for on demand analgesia and opioid consumption. PCB also decrease the incidence of opioid-associated nausea and vomiting, comparing to general anesthesia, and increase the number of patients, who was mobilized in the 1st day (sitting) and 2nd day (getting up) after surgery. PCB may reduce the incidence of MINS, although to assess this outcome more studies are needed.

Trial registration: Clinicaltrials.gov: NCT04648332, first registration date 1/12/2020.

Keywords: Postoperative pain, Psoas compartment block, Proximal femur fracture

\section{Background}

There are approximately 1 million femur fractures in the world each year [1] with significant impact on life expectancy and quality $[2,3]$, with high risk of respiratory, cardiac and thrombotic complications. Postoperative mortality may vary between 7 and $11 \%$ at 1 month, 16 and $28 \%$ at 6 month and 22 and $37 \%$ at 1 year [4]. Surgical treatment, perioperative care and early mobilization are important and associated with mortality, incidence of complications, length of hospital stay and survival [5].

Every third patient with femur fracture has severe pain, and another $30 \%$ moderate pain [6]. While effective perioperative pain management is associated with significantly better outcomes: reduced duration of hospitalization and the risk of delirium, early mobilization, lower risk of respiratory and cardiac complications [6].

The most common techniques of perioperative analgesia for proximal femur fractures are systemic analgesia, neuraxial (epidural) analgesia and peripheral nerve blocks - psoas compartment block. Intraoperatively, respectively, anaesthesia is provided by general anaesthesia, neuraxial (spinal) anaesthesia or compartment psoas block in combination with a sciatic nerve block. Systemic analgesia is often limited in this group of patients due contraindications (like chronic renal disease for nonsteroidal anti-inflammatory drugs (NSAIDs) or the development of side effects (respiratory depression, nausea and vomiting, sedation). Neuraxial anaesthesia also had limitations due to risk of hemodynamic complications (hypotension, bradycardia), which may lead to postoperative myocardial and renal injury, and contraindications in patients who already receive anticoagulant or antiplatelet therapy.

Psoas compartment block is a peripheral regional technique of anaesthesia and analgesia, which provides a block of the main components of the lumbar plexus - the femoral, lateral cutaneous nerve of the femur and sciatic nerve. In combination with the sciatic nerve block, the psoas compartment block provides effective anaesthesia of the entire lower extremity, with better hemodynamic stability, compared to epidural anaesthesia $[7,8]$.

The aim of our study was to compare the effectiveness and safety of different techniques of perioperative anaesthesia and anaesthesia in patients with fractures of the proximal femur: general anaesthesia with systemic postoperative analgesia, neuraxial (spinal) anaesthesia with systemic postoperative analgesia and prolonged compartment psoas block in combination with a sciatic nerve block (intraoperatively).

\section{Materials and methods}

A randomized controlled trial was conducted from January 2018 to August 2019 at the Into-Sana Medical Center (Odessa, Ukraine). The study design was approved by the Ethical Committee at Bogomolets National Medical University. Patients who planned osteosynthesis of the proximal femur and who met the inclusion criteria were randomized to 3 study groups in a 1:1 ratio (Fig. 1) using random assignment in blocks of four. The randomization sequence was generated using a computer algorithm [9]. Randomization and data analysis were conducted by an independent blinded member of the research team.

Criteria for inclusion in the study were: signed informed consent, age over 18 years. Exclusion criteria were: patient age less than 18 years, patient refusal, pregnancy and lactation, history of opiate addiction, severe comorbidities (traumatic brain injury; acute stroke; dementia; acute cerebrovascular accident; chronic heart failure (New York Heart Association Functional Classification, NYHA, class III-IV), respiratory failure, renal failure with decreased creatinine clearance less than $30 \mathrm{ml} /$ min / $1.73 \mathrm{~m} 2$, hepatic insufficiency class $\mathrm{C}$ according to Child-Pugh).

For patients in group 1, after including in the study, ultrasound-guided Shamrock $\mathrm{CPB}$ with bupivacaine $0.125 \% 6-8 \mathrm{ml} / \mathrm{h}$ was performed. Intraoperative anesthesia was provided with a bupivacaine bolus of $0.5 \%$ $200 \mathrm{mg}$ in a lumbar catheter and a sciatic nerve block (neurostimulator identification) with $1.5 \% 450 \mathrm{mg}$ of lidocaine. Postoperative analgesia include prolonged $\mathrm{CPB}$ with bupivacaine $0.125 \% 6-8 \mathrm{ml} / \mathrm{h}$. Also paracetamol $3 \mathrm{~g} /$ day and dexketoprofen $75 \mathrm{mg} /$ day was prescribed.

For patients in group 2 and 3 preoperative analgesia include paracetamol $3 \mathrm{~g} /$ day and dexketoprofen $75 \mathrm{mg} /$ day. On-demand, nalbuphine $5 \mathrm{mg}$ SC was used for analgesia. 
Patients who are scheduled for osteosynthesis of the proximal femur

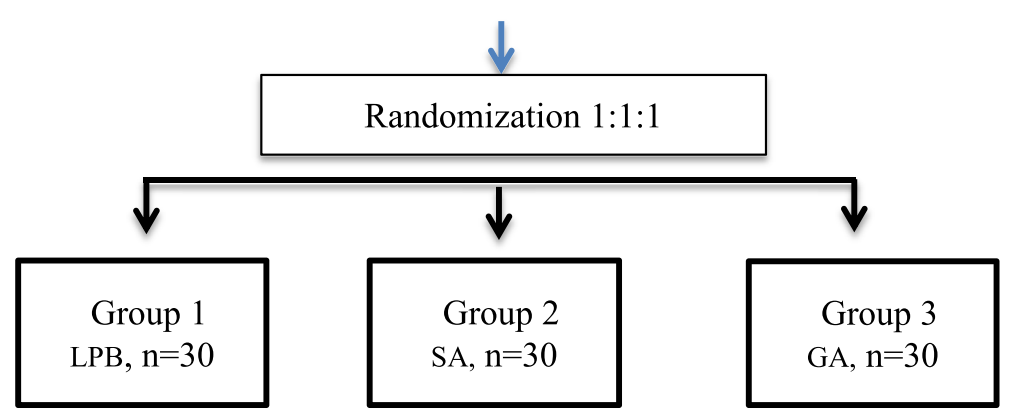

Fig. 1 Distribution of patients in study groups: PCB - psoas compartment block, SA - spinal anesthesia, GA - general anesthesia

In group 2 intraoperative spinal anaesthesia were performed at the level of L3-L4 with hyperbaric bupivacaine $10-15 \mathrm{mg}$. Patients in groups 1 and 2 receive intraoperative sedation with propofol $1 \%$ with a target level of sedation RASS from 0 to -2 .

Group 3 patients underwent general sevoflurane inhalation anaesthesia with fentanyl infusion for analgesia.

All patients received paracetamol $3 \mathrm{~g} /$ day and dexketoprofen $75 \mathrm{mg} /$ day during hospitalization. On-demand, nalbuphine $5 \mathrm{mg} \mathrm{SC}$ was used for analgesia.

The primary efficacy outcome was: postoperative nalbuphine consumption during first $24 \mathrm{~h}$ and cumulative during hospital stay. SC injection of $5 \mathrm{mg}$ nalbuphine was used as analgesic on-demand.

The secondary efficacy outcomes were:

- ICU length of stay and the total duration of hospitalization

- number of patients who had severe pain after surgery

- incidence of on-demand analgesia (nalbuphine $5 \mathrm{mg}$ $\mathrm{SC})$

- sleep quality (from 0 to 10 , where 0 - very bad / no sleep, 10 - excellent sleep)

- postoperative mobilization time (sitting in bed and getting to his feet)

The safety assessment criteria were complications and side effects throughout the perioperative period. Criteria for myocardial injury after noncardiac surgery (MINS) were increased highly sensitive troponin $\mathrm{T}$ (hsTnT) more than $20 \mathrm{ng} / \mathrm{l}$ with or without symptoms of ischemia. We did not include patients when increased troponin was thought to be associated with other noncardiac causes (sepsis, pulmonary embolism) or a consequence of chronic myocardial injury (hsTnT before operation $20 \mathrm{ng}$ $/ 1$ and more) [10]. HsTnT was performed for all patients before and in $48 \mathrm{~h}$ after surgery. Criteria for nosocomial pneumonia were new pulmonary infiltrates of infectious origin (with fever, sputum, leucocytosis, procalcitonin elevation and decreased oxygenation) that occurred $48 \mathrm{~h}$ or later after hospitalization [11]. The criteria of delirium were considered: disturbance of attention and consciousness; changes that have developed acutely (hours or days) and fluctuate during the day; cognitive impairment (memory, speech, orientation, perception, vision); there is no evidence that this condition has developed as a result of a medical condition, intoxication or withdrawal of certain substances, side effects of drugs [12].

All patients underwent intraoperative monitoring: ECG monitoring, blood pressure and pulse oximetry, BIS (group 3), capnography (group 3), postoperatively performed round-the-clock monitoring of vital signs. Pain was measured every $2 \mathrm{~h}$ during first $48 \mathrm{~h}$ after surgery (excluding night time) with numeric pain rating scale (NPRS), where 0 - no pain, 10 - most severe pain you can imagine. The criteria for severe postoperative pain was pain measured as 7 or more during $30 \%$ or more time after surgery.

Sample size was calculated using MedCalc Software version 16.8.4 (MedCalc Software bvba, Acacialaan 22, 8400 Ostend, Belgium). Based on minimum mean difference of $25 \%$ in morphine consumption [13] with $\alpha=0.01$ and $\beta=0.20$, sample size for each group was estimated as 20 . So, we include 30 patients in each group. Statistical analysis was performed with Statistica 8.0 programs. Categorical data are presented as proportions, continuous - as the median and 25-75 quadrantiles. The Chisquare test was used to determine the normality of the 
data distribution in the sample, and most of the results in the study are nonparametric. The Kruskal-Wallis test to compare differences between multiple groups, MannWhitney test to compare differences between two groups and the Fisher double test to compare proportions were used. The probability of error (p) was considered insignificant at $p<0.05$.

\section{Results}

The study included 90 patients (30 in each group, respectively). Patients in different groups did not differ statistically in demographics and comorbidities (Table 1). There were also no differences in the duration of hospitalization in the intensive care unit - gr.1 72 [70-75], gr.2 74 [7276 ], gr.3 72 [70-75] hours respectively $(p=0.29$, KruskalWallis test), and the total duration of hospitalization - gr.1144 [170-184], gr.2170 [148-188], gr.3178 [144200] hours respectively ( $p=0.5$, Kruskal-Wallis test).

Patients in group 1 had significantly lower nalbuphine consumption in the first $24 \mathrm{~h}$ after surgery and total during hospitalization $(0[0-5] \mathrm{mg}$ versus 15 [10-20] and 20 [15-25] $\mathrm{mg}$ in the first $24 \mathrm{~h}$ in groups 2 and 3 , respectively $(p<0.001)$, the lowest number of patients with severe pain (10\% vs. 47 and $60 \%$ in groups 2 and 3, respectively, $p<0.05)$, lower frequency of on-demand analgesia $(0$ $[0-1]$ vs. $3[2-4]$ and $4[3,4]$ in groups 2 and 3, respectively), better sleep quality (8 [7-9] vs. $6[5-7]$ and 4 [3, $4]$ in groups 2 and 3 , respectively, $p<0.001$ ), significantly faster mobilization after surgery - sitting in bed and getting to his feet (see Table 2).

No serious complications or side effects were reported. The study groups had no significant differences in the incidence of hypertension, bradycardia, tachycardia (Table 3). Hypotension was significantly more common in group 2 spinal anaesthesia (OR 995

Table 1 Demographic characteristics of patients in study groups

\begin{tabular}{lllll}
\hline Indicator/group & Group 1 & Group 2 & Group 3 & $p$ \\
\hline Gender, female, n (\%) & $21 / 9(70)$ & $21 / 9(70)$ & $22 / 8(73)$ & $p>0,05^{1}$ \\
Age $^{*}$ & $72[68-73]$ & $72[70-73]$ & $73[72-74]$ & $p=0,14^{2}$ \\
$\begin{array}{l}\text { Concomitant pathology: } \\
\quad \text { Diabetes mellitus, }\end{array}$ & $3 / 27(10)$ & $4 / 26(13)$ & $4 / 26(13)$ & $p>0,05^{1}$ \\
n (\%) & & & & \\
$\quad$ Hypertension, n (\%) & $6 / 24(20)$ & $7 / 23(23)$ & $9 / 21(30)$ & $p>0,05^{1}$ \\
$\quad$ Chronic kidney dis- & $2 / 28(7)$ & $2 / 28(7)$ & $2 / 28(7)$ & $p>0,05^{1}$ \\
ease, n (\%) & & & & \\
$\quad$ COPD, n (\%) & $2 / 28(7)$ & $1 / 29(3)$ & $2 / 28(7)$ & $p>0,05^{1}$ \\
Other: & $6 / 24(20)$ & $8 / 22(27)$ & $6 / 24(20)$ & $p>0,05^{1}$ \\
\hline
\end{tabular}

Unless specified otherwise, values are expressed as medians, with $25-75 \%$ interquartile ranges in parentheses. COPD Chronic obstructive pulmonary disease

1 - Fisher's exact test, ${ }^{2}$ - Kruskal-Wallis test
CI $1.9-47, p=0.004)$. Nausea and vomiting occurred significantly more often in control group 3 (general anaesthesia) compared with the study group 1 (OR 795 CI $1,3-35, p=0,02)$. MINS was diagnosed significantly more often in control groups 2 and 3 compared with study group 1 (OR 995 CI 1,01-77, $\mathrm{p}=0,048$ for group 2 and OR 1195 CI 1,2-91, $p=0,03$ for group 3). However, none of the patients had symptoms of myocardial ischemia and / or myocardial infarction. Nosocomial pneumonia was diagnosed in 1 patient in group 2, and 4 patients in group 3, no significant difference in the risk of nosocomial pneumonia was found. Detailed information on the frequency of complications in the groups is given in the Table 3.

\section{Discussion}

Perioperative analgesia in elderly patients with fractures of the proximal femur become a challenge due to risks of cardiac, thrombotic, pulmonary complications, high comorbidity incidence and severity, already prescribed drug therapy (anticoagulants). Although effective pain management in this patients group plays a key role in early mobilization, decreasing the complications rate, including delirium, survival and life expectancy after injury.

In our randomized controlled trial, we compared the perioperative use of the psoas compartment block with other techniques of anesthesia - spinal and general anesthesia with systemic analgesia before and after surgery. According to the results of this study, the most effective analgesic technique was prolonged compartment psoas block, started from admission to the hospital and continued postoperatively. PCB was associated with significantly lower number of patients with severe pain, lower opioid consumption and lower on demand analgesia incidence, better sleep quality, and faster mobilization, lower risk of opioid-associated side effects (nausea and vomiting) and MINS. We did not find a difference in the nosocomial pneumonia and delirium incidence.

Another studies had similar results, Canakci et al. [14] reported, that the psoas compartment block (PCB) provide longer time to first analgesia, comparing with the spinal anesthesia (SA). Although PCB group had significantly lower opioid consumption - $300 \mathrm{mg}$ tramadol versus $1500 \mathrm{mg}$ in SA group. In our study PCB patients also had significantly lower opioid (nalbufin) consumption, comparing with both control groups (Table 2).

Meta-analysis of 31 trials published in 2017 [15] showed that peripheral nerve blocks reduced pain on movement within $30 \mathrm{~min}$ of block placement, in this study we also showed the efficacy of PCB for pain management after femur surgery - the number of patients 
Table 2 Efficacy outcomes

\begin{tabular}{|c|c|c|c|}
\hline Indicator/group & Group 1 & Group 2 & Group 3 \\
\hline Nalbuphine consumption during first $24 \mathrm{~h}$ after surgery, mg & $0[0-5]$ & $15[10-20]^{3}$ & $20[15-25]^{3}$ \\
\hline Total nalbuphine consumption during hospitalization, mg & $5[0-10]$ & $45[40-50]$ & $50[40-60]$ \\
\hline Pain at rest in the first $24 \mathrm{~h}$ after surgery, NPRS & $3[2-4]$ & $5[3-6]$ & $6[4-7]$ \\
\hline Pain during movements in the first $24 \mathrm{~h}$ after surgery, NPRS & $4[3-5]$ & $6[4-7]$ & $7[5-8]$ \\
\hline Number of patients with severe pain, $n(\%)$ & $3 / 27(10)^{1}$ & $14 / 16(47)$ & $18 / 12(60)^{1}$ \\
\hline Analgesia on-demand, $\mathrm{n}$ & $0[0-1]^{1}$ & $3[2-4]$ & $4[3-4]$ \\
\hline Sleep quality (0 to 10$)$ & $8[7-9]^{1}$ & $6[5-7]$ & $4[3-5]$ \\
\hline Mobilization (sitting) on 1st day, n (\%) & $20 / 10(67)^{2}$ & 10/20 (33) & $3 / 27(10)$ \\
\hline Mobilization (getting up) on 1st day, n (\%) & $4 / 26(13)$ & $0 / 30$ & $0 / 30$ \\
\hline Mobilization (sitting) on 2nd days, n (\%) & 29/1 (3) & $25 / 5(83)$ & $20 / 10(67)^{1}$ \\
\hline Mobilization (getting up) on 2nd days, n (\%) & $27 / 3(90)^{2}$ & $10 / 20(33)$ & $8 / 22(27)$ \\
\hline
\end{tabular}

Unless specified otherwise, values are expressed as medians, with $25-75 \%$ interquartile ranges. NRS numeric pain rating scale. ${ }^{1}-{\text { Fisher's exact test, } p<0,05 ;{ }^{2}-}$ Fisher's exact test, $p<0,001,{ }^{3}$ - Mann-Whitney test

with severe pain and analgesia on demand was significantly lower in PCB group. They also did not find a difference in the risk of acute confusional state (risk ratio (RR) $0.69,95 \%$ CI 0.38 to $1.27 ; \mathrm{I}^{2}=48 \%$ ), as we didn't too in this study. Three trials with 131 participants reported decreased risk for pneumonia (RR 0.41, $95 \%$ CI 0.19 to $0.89 ; \mathrm{I}^{2}=3 \%$ ), in our study we didn't find this, maybe due to not large enough study groups. The authors did not find a difference in risk of myocardial ischaemia or death within 6 months, but the number of participants included was well below the optimal information size for these two outcomes. In our study we also did not find this difference, although the incidence of MINS was significantly lower in PCB group versus SA and GA groups. Two trials with 155 participants reported that peripheral nerve blocks also reduced time to first mobilization after surgery (mean difference $-11.25 \mathrm{~h}, 95 \% \mathrm{CI}-14.34$ to $-8.15 \mathrm{~h} ; \mathrm{I}^{2}=52 \%$ ), the same results we had in our study - number of patients, who was mobilizated in the 1st day (sitting)

Table 3 Frequency of complications and side effects in groups

\begin{tabular}{lllll}
\hline Indicator / group & Group 1 & Group 2 & Group 3 & $p$ \\
\hline Hypotension, n (\%) & $1 / 29$ & $12 / 18^{1}$ & $4 / 26$ & - \\
Hypertension, n (\%) & $2 / 28$ & $1 / 29$ & $2 / 28$ & $p>0,05$ \\
Bradycardia, n (\%) & $1 / 29$ & $3 / 27$ & $1 / 29$ & $p>0,05$ \\
Tachycardia, n (\%) & $4 / 26$ & $2 / 28$ & $1 / 29$ & $p>0,05$ \\
MINS, n (\%) & $1 / 29^{1}$ & $7 / 23$ & $8 / 22$ & - \\
Nosocomial pneumonia, n (\%) & $0 / 30$ & $1 / 29$ & $4 / 26$ & $p>0,05$ \\
Delirium, n (\%) & $0 / 30$ & $1 / 29$ & $1 / 29$ & $p>0,05$ \\
Nausea / vomiting, n (\%) & $2 / 28$ & $5 / 25$ & $10 / 20^{1}$ & - \\
Itching, n (\%) & $0 / 30$ & $1 / 29$ & $2 / 28$ & $p>0,05$ \\
\hline
\end{tabular}

Fisher's exact test: $1-p<0,05 ; 2-p<0,001$ and 2nd day (getting up) after surgery was significantly higher in the PCB group.

The limitations of this study include the partially blinded design with absence of placebo control and the small sample size $(n=90)$, which make it difficult to made final conclusions about efficacy and safety of the PCB.

Nevertheless, this trial showed that perioperative PCB for elderly patients with proximal femur fracture, is effective to decrease the number of patients with severe pain, the number of on demand analgesia and opioid consumption. PCB also reduce the incidence of opioid-associated nausea and vomiting, the incidence of MINS and increase number of patients, who could sit in the 1st day after surgery and get up on the 2nd day.

\section{Conclusion}

Perioperative PCB in elderly patients with a proximal femur fracture could be an effective analgesia technique, as it decrease the number of patients with severe pain, need for on demand analgesia and opioid consumption. PCB also decrease the incidence of opioidassociated nausea and vomiting, comparing to general anesthesia, and increase the number of patients, who was mobilized in the 1st day (sitting) and 2nd day (getting up) after surgery. PCB may reduce the incidence of MINS, although to assess this outcome more studies are needed.

\section{Abbreviations}

ASA: American Society of Anesthesiology; BIS: Bispectral index; COPD: Chronic obstructive pulmonary disease; ECG: Electrocardiogram; FNB: Femoral nerve block; GA: General anesthesia; ICU: Intensive care unit; NRPS: Numeric rating pain scale; NSAIDs: Nonsteroidal anti-inflammatory drugs; PCB: Psoas 
compartment block; RASS: Richmond Agitation-Sedation Scale; SA: Spinal anesthesia; USA: Underwent spinal anesthesia; VRS: Verbal rating scale.

\section{Supplementary Information}

The online version contains supplementary material available at https://doi. org/10.1186/s12871-021-01473-9.

\section{Additional file 1}

\section{Acknowledgements}

No acknowledgements to declare.

\section{Authors' contributions}

IK performed the randomization and carried out the statistical analysis. KB carried out the acquisition and interpretation of data. IT and VA conceived and designed the study and critically revised the manuscript. UK was involved in drafting and revising the manuscript. All authors read and approved the final manuscript.

\section{Funding}

No funding was received for this study.

\section{Availability of data and materials}

Reasonable requests for access to the datasets used and/or analysed during the study can be made to the corresponding author.

\section{Declarations}

\section{Ethics approval and consent to participate}

This study was approved by the Ethical Committee of Bogomolets National Medical University. All participants gave their written, informed consent to participate in the study. All methods were performed in accordance with the relevant guidelines and regulations.

\section{Consent for publication}

All participants gave their signed informed consent to the publication of study data.

\section{Competing interests}

The authors declare that they have no competing interests.

\section{Author details}

'Postgraduate Department of Surgery, Anesthesiology and Intensive Care, Bogomolets National Medical University, 13 T. Shevchenko Boulevard, Kiev 01601, Ukraine. ${ }^{2}$ Department of Anesthesiology and Intensive Care, Medical Center "Into-Sana", Varnenska street 2, Odesa 65065, Ukraine.

Received: 30 October 2020 Accepted: 28 September 2021

Published online: 25 October 2021

\section{References}

1. Cheng SY, Levy AR, Lefaivre KA, et al. Geographic trends in incidence of hip fractures: a comprehensive literature review. Osteoporos Int. 2011;22(10):C.2575-86.

2. Marufu TC, White SM, Griffiths R, et al. Prediction of 30-day mortality after hip fracture surgery by the Nottingham hip fracture score and the surgical outcome risk tool. Anaesthesia. 2016;71:515-21.

3. White SM, Moppett IK, Griffiths R, et al. Secondary analysis of outcomes after 11,085 hip fracture operations from the prospective UK Anaesthesia Sprint audit of practice (ASAP-2). Anaesthesia. 2016;71:506-14.

4. Smith PAC, Bardsley M. Focus on hip fracture: trends in emergency admissions for fractured neck of femur, 2001 to 2011: The Health
Foundation and the Nuffield Trust; 2013. http://www.nuffieldtrust.org. uk/sites/files/nuffield/publication/131010_focus-on-hip-fracture.pdf. Accessed 20 Dec 2016.

5. Rowlands M, Gv W, Bradley J, et al. Femoral nerve block intervention in neck of femur fracture (FINOF): a randomised controlled trial. BMJ Open. 2018:8:e019650.

6. Dixon J, Ashton F, Baker P. Assessment and early management of pain in hip fractures: the impact of paracetamol. Geriatr Orthop Surg Rehabil. 2018;9:C.2151.

7. Zhang $X$, Zhou $Y, C$ Chen $L$, et al. Anesthesia and postoperative analgesia during unilateral lower-extremity fracture surgeries using multiple injections through catheters beside the lumbar plexus or sciatic nerve. Ther Clin Risk Manag. 2013;9:C.299-302.

8. Demirel I, Ozer AB, Duzgol O, et al. Comparison of unilateral spinal anesthesia and L1 paravertebral block combined with psoas compartment and sciatic nerve block in patients to undergo partial hip prosthesis. Eur Rev Med Pharmacol Sci. 2014;18(7):C.1067-72.

9. Mansour A. Femoral nerve block versus spinal anesthesia for lower limb peripheral vascular surgery. Alexandria J Anaesth Intensive Care. 2006;9(1):44-50.

10. Writing Committee for the VISION Study Investigators. Association of postoperative high-sensitivity troponin levels with myocardial Injury and 30-day mortality among patients undergoing noncardiac surgery. JAMA. 2017;317(16):C.1642-51.

11. Cunha BA. Pneumonia Essentials. 3rd ed. Royal Oak: Physicians Press; 2010.

12. American Psychiatric Association. Diagnostic and statistical manual of mental disorders (DSM- $\left.{ }^{\circledR}\right)$. 5th ed. Arlington: American Psychiatric Association Publishing; 2013. p. 596-601.

13. Arce Villalobos M, Veneziano G, lobst C, Miller R, Walch AG, Roth C, et al. Regional anesthesia for pain management after orthopedic procedures for treatment of lower extremity length discrepancy. J Pain Res. 2020;13:547-52.

14. Canakci E, Unal D, Guzel Y. The effect of unilateral spinal anaesthesia and psoas compartment with sciatic block on the postoperative pain management in total knee artroplastic surgery. Pain Res Manag. 2017;2017:4127424. https://doi.org/10.1155/2017/4127424 Epub 2017 Jan 31.

15. Guay J, Parker MJ, Griffiths R, Kopp S. Peripheral nerve blocks for hip fractures. Cochrane Database Syst Rev 2017, Issue 5. Art. No.: CD001159. DOI: https://doi.org/10.1002/14651858.CD001159.pub2.

16. Mueller SW, Preslaski CR, Kiser TH, et al. A randomized, double-blind, placebo-controlled dose range study of dexmedetomidine as adjunctive therapy for alcohol withdrawal. Crit Care Med. 2014;42(5):1131-9.

\section{Publisher's Note}

Springer Nature remains neutral with regard to jurisdictional claims in published maps and institutional affiliations.

Ready to submit your research? Choose BMC and benefit from:

- fast, convenient online submission

- thorough peer review by experienced researchers in your field

- rapid publication on acceptance

- support for research data, including large and complex data types

- gold Open Access which fosters wider collaboration and increased citations

- maximum visibility for your research: over 100M website views per year

At BMC, research is always in progress.

Learn more biomedcentral.com/submissions 